\title{
USOS Y BENEFICIOS DE LA HISTORIA ORAL
}

Antonio M. Rodríguez García, Rosa M. Luque Pérez, Ana M. Navas Sánchez. Universidad de Granada

Supervisado por la profesora Erika González García. Departamento de Pedagogía. Universidad de Granada Fecha de recepción: 30 de mayo de 2014.

Fecha de revisión: 5 de junio de 2014.

Fecha de aceptación: 5 de junio de 2014.

\section{Resumen}

La historia oral es una metodología propia de las Ciencias Sociales, aunque puede extenderse mucho más allá de ellas. Supone una metodología de investigación rica en el aprendizaje y conocimiento de diversos sucesos, acciones, procesos y circunstancias pasadas, y que son relatadas y recogidas a través de la voz, en primera persona, de un sujeto o grupo de ellos.

Palabras clave: Historia Oral; Metodología; Ciencias Sociales

\section{Introducción}

En la era de la comunicación y la sociedad conocimiento en la que estamos inmersos y de la que somos testigos, la relevancia que tiene el relato de la historia es de vital importancia, especialmente cuando se trata de dar voz a aquellas personas que han sido partícipes de algún momento histórico determinado y que pueden aportar sus visiones acerca de un hecho, suceso o ámbito específico.

El proceso de uso de la historia oral no se reduce únicamente a lo que entendemos por el concepto de "historia", o cuando hacemos uso de lo histórico, es decir, a una serie de acontecimientos sucesivos con fechas y períodos determinados, sino que el uso de la historia oral implica una serie de sucesos, experiencias y, desde luego, sentimientos. Cuando se hace uso de la historia oral se da oportunidad a una persona o colectivo a hablar, a contar sus vivencias, experiencias, formas entender y dar significado a su propia vida y así, ayudarnos a comprender la nuestra propia, nuestro presente.

A través de nuestro recorrido de indagación pretenderemos dar a conocer el beneficio de la historia oral como material y recurso para analizar lo histórico, así como dar a conocer algunas implicaciones que supone el uso de esta metodología. Además, pretendemos realzar la importancia que tiene el uso del método de recogida de información sobre testimonios orales para dar voz a personas silenciadas, así como el traslado de estas experiencias a los procesos de enseñanza-aprendizaje, en el que podamos ver los diferentes beneficios que implica el uso de la historiografía oral en el aula de educación.

Cuando hacemos uso, por tanto, de la historia oral podemos obtener una serie de visiones que son narradas en primera persona desde un punto muy subjetivo, ya que en ellas se recogen una serie de vivencias y experiencias vividas por un colectivo de personas en un momento determinado de su vida o en un largo período de la misma, y 
a través de las cuales se aportan nuevos planteamientos y visiones a la evidencia investigada lo que supone, además, la complementariedad de diferentes visiones así como la contrastación de las mismas.

\section{Aproximación al concepto y origen de la historia oral}

El término de "Historia Oral" apareció por Allan Nevis en el año 1948 (Folguera, 1994). A partir de ahí, poco a poco, vino siendo estudiado por distintos autores. Desde el punto de la investigación, la historia oral se define como una técnica de investigación contemporánea.

La aparición de la historia oral como nuevo recurso metodológico supuso una gran revolución en la docencia de la historia y en la historiografía en general, ya que la técnica y el método que emplea no solo nos permite la recuperación de testimonios, sino que también nos facilita la escritura de otro tipo de historia, la de aquellas personas que han sido silenciadas u olvidadas en una determinada época o suceso histórico.

Generalmente, se suele acuñar el uso de historia oral como campo metodológico asociado a las ciencias sociales (Graciela, s.f.), en el que diversas disciplinas permiten que se haga una comprensión más profunda en la vida de los sujetos entrevistados, como pueden ser los estudios derivados de la sociología, de la antropología, lingüística, la educación o la psicología. Se trata de un método cualitativo que identifica información de corte subjetivo acerca de la vida de una persona determinada que narra un momento específico.

El uso de la historia oral ha sido altamente cuestionado en aspectos que se refieren a su fiabilidad, aplicabilidad en el uso de lo histórico, complementariedad, etc. Según Ruth Edmonds Hill, en Folguera, 1994, la historia oral es principalmente una labor de recuperación de testimonios olvidados. Indudablemente, el carácter renovador de la historia oral consiste, precisamente, en la aproximación a la realidad de aquellas personas que por diferentes circunstancias se encontraban fuera de las esferas o los estratos de poder.

La historia oral, implica la narración de hechos y sucesos pasados que son expresados a viva voz, con palabras y que, a su vez, permiten que salgan a la luz testimonios de personas desconocidas, "gentes sin historia", fomentado la recuperación de la memoria histórica a través de las vivencias, las experiencias, las prácticas a lo largo de la vida, sensaciones vividas... y que son recogidas de manera escrita. (Jiménez, 2009)

Tiene un gran potencial educativo, ya que permite la recopilación y recuperación de la memoria de aquellas personas que vivieron en otra época distinta a la nuestra, en un momento histórico concreto, contextualizado y que, por lo tanto, puede ayudarnos a comprender el presente que estamos viviendo, el conocer por qué las cosas han sucedido de la manera que lo han hecho. Ahora bien, una de las características manifiestas del uso de la historia oral es su gran carácter subjetivo (Graciela, sf.) y la intervención de la memoria y los recuerdos, lo que nos puede dificultar o facilitar nuestra tarea de recogida de información oral.

El uso de la historia oral permite que las personas que participan en ella puedan desarrollar una serie de capacidades y destrezas personales y profesionales que faciliten el conocimiento de lo histórico. Dichos proyectos permiten impulsar la 
investigación en muy diversos ámbitos: escuelas, institutos, universidades, museos, centros de investigación, etc.

La historia de desarrollo como recurso metodológico de la historia es una herramienta que nos facilita, por tanto, conocer hechos pasados, vidas silenciadas, la vinculación entre el pasado y el presente, su evolución, ver cómo ha cambiado las cosas, etc. A través de ella se recurre a la memoria y experiencia particular del entrevistado para así acercarse a la vida cotidiana y a las formas de vida no registradas por las fuentes tradicionales. Las vivencias son narrativas solicitadas a una persona por parte de quien pretende recoger sus recuerdos de experiencias, trayectos y subjetividades, abarcando en el periodo de su vida que va desde los primeros tiempos hasta el momento en que transcurren tales encuentros. (Costa y Magalhaes, 2001)

A través de la historia oral se nos permite conocer el mundo de la persona desde dentro, es decir, a través del punto de vista de la implicada, es decir, se nos permite disfrutar de una mirada personal e íntima de su relato de vida personal.

\section{Historia Oral, "dar voz a las personas silenciadas"}

El sector más marginado y silenciado a lo largo de la historia han sido aquellas personas pertenecientes a las clases más bajas, las mujeres, los sectores populares, el mundo del trabajo, los movimientos migratorios (Graciela, s.f.), entre otros, por lo que en la actualidad, y debido al carácter de esta metodología, el estudio de estos sectores de población suelen ser grandes líneas de investigación relacionadas con la historia oral. A partir de dichas fuentes, se da voz y luz a una serie de memorias obviadas por la historia oficial, es decir por la "historia dominante".

A través de los recuerdos podemos ver como diversas personas pensaron, vieron, vivieron y construyeron su mundo. Los relatos orales nos dirigen e introducen al conocimiento de la experiencia individual y colectiva a la vez. Cabe destacar, que a través de la historia oral no se muestra una verdad objetiva, sino que se trata de una experiencia subjetiva, pues no muestra verdades precisas o reconstrucciones veraces. Pero a su vez, las experiencias personales (subjetivas) nos ayudan a comprender la experiencia general de un grupo más amplio de personas. La subjetividad de esta metodología es porque ella se basa en los recuerdos, en la memoria. Por ello, es muy importante tener presente la selección de los recuerdos, lo que puede alterar la imagen que nos hacemos acerca de la temática que estamos estudiando, de esa persona y de esa situación concreta que investigamos. Este binomio subjetividadobjetividad puede evitarse, o al menos suavizarse al complementar esta técnica con la información de otras fuentes historiográficas.

La historia de vida se puede utilizar para aportar testimonios de primera mano en la investigación historiográfica. Además, cabe destacar especialmente el potencial que poseen estas fuentes para reconstruir la historia de las mujeres, y ver cómo estás han participado a lo largo de la historia en diferentes sectores: educativo, social, familiar, entre otros. Al mismo tiempo, sirve para dar respuesta a aquellos problemas que se derivan de la ausencia de fuentes escritas referidas a un determinado periodo y a una determinada temática.

\section{Implicaciones y beneficios del uso de la historia oral en el ámbito educativo}

La historia oral permite la recuperación sistemática de los discursos a través de la palabra. Es por ello que se presenta como una técnica de investigación muy adecuada para el estudio del ámbito educativo, ya que si queremos comprender lo que está 
pasando en el presente se hace necesaria una mirada hacia el pasado, a nuestra propia para dar a conocer las visiones particulares de las personas que no dan respuesta a los enfoques procedentes de la hegemonía cultural.

El uso de la historia oral en el ámbito educativo nos brinda numerosos beneficios. Por un lado nos permite humanizar la historia, al no basar la construcción de esta disciplina en base a hechos, datos, fechas..., sino que permite la elaboración de sucesos históricos a través de vivencias personales.

Otro de los beneficios que se encuentran en el uso de la historia oral es que aproxima al alumnado a procesos de investigación, lo que conlleva una reconstrucción más atractiva del conocimiento histórico para los mismos (Graciela, s.f.). Asimismo, enriquece el proceso de enseñanza-aprendizaje, ya que se presenta como un trabajo colaborativo entre profesores y alumnos, lo cual beneficiara la construcción de un aprendizaje simbólico y significativo para el alumnado. Por otro lado, el uso de la misma constituye una oportunidad para fomentar el trabajo autónomo del alumno y su participación activa en el proceso de aprendizaje; en definitiva, favorece a la construcción interdisciplinar del conocimiento. Esta tarea también puede ser planteada de forma transversal en diferentes asignaturas del currículum, consiguiendo así un conocimiento menos sesgado o formal, generalmente propio de los libros de textos escolares y de la estructura fragmentada del currículum (Jiménez, 2009). Además, Costa, H. y Magalhaes, M. J. (2001) afirman que las historias orales ayudan a la formación inicial de los profesores, ya que contribuyen a la elaboración del propio conocimiento de la persona.

La Historia Oral, al recoger los testimonios de "voces silenciadas", fomenta en el alumnado el análisis de determinados grupos sociales, lo cual abre la puerta para trabajar otros temas en el aula como la exclusión social, el androcentrismo histórico, identificación de procesos de identificación con el "otro", aproximación a sistemas y/o herramientas de inclusión, análisis reflexivos sobre prácticas educativas segregadoras, etc. El proyecto de historia oral promueve el debate y la cooperación entre los estudiantes, permitiendo así el desarrollo de la capacidad lingüística tanto oral, como escrita.

Otra ventaja que debemos de aludir del desempeño de este trabajo por parte de los alumnos es que al acceder al conocimiento histórico de manera innovadora, el alumno toma contacto con el medio de forma mucho más participativa lo que genera una mayor implicación por su parte, fomentando así que el alumno "sienta" como propio el conocimiento que se está elaborando. Asimismo, tal implicación permite que el alumno lleve a cabo procesos de reflexión en los cuales se establezcan relaciones entre las experiencias contadas y lo que lee en otras fuentes de información como por ejemplo en los libros de texto escolares, fuentes historiográficas, etc.

Los beneficios anteriormente expuestos responden a las competencias planteadas por el Espacio Europeo de Educación Superior; algunas de ellas son: aproximación del alumnado a trabajos de investigación histórico-educativos; creación de conciencia histórica en el alumnado; recuperación de testimonios de personas con "voces silenciadas"; realización de análisis comparativos, lo que fomenta el uso del dialogo y la comunicación en el papel del alumno; se introduce el uso de distintas fuentes históricas en las aulas; se fomenta el desarrollo de capacidades de análisis, síntesis, crítica y reflexión en los alumnos; se acerca al alumno a tiempos pasados desde el conocimiento de experiencias personales y únicas, lo que refleja una visión no androcéntrica sobre la historia. (Jiménez, 2009) 
Del mismo modo, la historia oral y, especialmente, la entrevista pueden contribuir a estrechar las relaciones intergeneracionales entre los sujetos más pequeños y los más mayores, en los que ambos se hacen partícipes de la creación de un nuevo relato, transformándose en sujetos activos de vital importancia en el proceso de recogida de la información. Además, en el caso de las personas mayores puede contribuir a una subida de la autoestima y un sentimiento de valía debido al interés que se muestra en conocer la vida de su persona.

El estudio de los distintos relatos biográficos nos brindará una serie de oportunidades para conocer una información minuciosa y detallada sobre la realidad, pero también sentimientos y emociones personales muy interesantes para conocer el impacto real de cambio y complejidad de las relaciones sociales primarias. (Grana y Alonso, 2009). Esta recuperación de la experiencia es una de las fuentes más importantes para reconocer el funcionamiento de la sociedad y de la vida en sí, ya que a través del recuerdo autonarrado comprendemos nuestra vida, en un relato en el que el autor, el narrador y el personaje son una misma persona.

La historia oral y las vivencias particulares (Costa y Magalhaes, 2001) nos ofrecen una oportunidad para estudiar los distintos problemas sociales así como la posibilidad de darles solución, con el objetivo de perseguir una sociedad más justa e igualitaria, donde se reconozca la voz de la mujer a lo largo de la historia y que, anteriormente, no habían sido recogidas.

Según Costa y Magalhaes, (2001) las historias de vida pueden constituir un poderoso dispositivo pedagógico para la formación inicial de profesores y alumnos. Más aún, las historias de vida pueden constituirse también como un vehículo de "concienciación", conduciendo hacia una ciudadanía plena en sus "propios términos". Así mismo, son una poderosa herramienta en el aprendizaje colectivo sobre los mecanismos de dominación y opresión y en la preparación para la acción transformadora. Así, las autoras consideran que partiendo del trabajo sobre sus historias de vida, las personas pueden alcanzar su propia transformación personal y social.

\section{Principales problemas de la Historia Oral}

La historia oral presenta fuertes limitaciones debido a la naturaleza de esta técnica, ya que el testimonio individual suscita una gran subjetividad y relatividad, y las técnicas de recogida de la información (las entrevistas) pueden ser objeto de grandes errores y omisiones sobre fechas, datos,...Aunque suscite grandes limitaciones, la historia oral está indicada para algunas áreas concretas de historia: social, local, familiar, mujeres, escuelas, institutos, universidades, museos, centros de investigación, etc. (Folguera, 1994)

Podríamos afirmar que la historia oral no pretende sustituir otro tipo de investigación historiográfica, pero sí que dicha técnica puede cambiar el enfoque de la indagación que se esté llevando a cabo al recoger los testimonios de las personas que han sido olvidadas a la hora de construir la historia.

Por lo general, en la investigación historiográfica la fuente oral no se presenta como única, sino como complementaria en aras de confirmar, constatar y contrastar aquellas otras fuentes utilizadas. Los testimonios recogidos pueden ser de gran ayuda para ver la historia desde otro punto de vista y cumplimentar visiones que sí han sido registradas. 
Siguiendo con las críticas, una de las más frecuentes ha sido cuestionar la fiabilidad de la fuente oral debido a condicionamientos, principalmente, fisiológicos: edad de las personas encuestadas, enfermedades, pérdidas de memoria, entre otros. Además, resalta la problemática de que las vivencias experimentadas poseen un gran carácter subjetivo. Las personas pueden elegir qué recordar, qué omitir, qué contar y qué guardarse para ellos, así como la forma de hacerlo, lo que influye en la narración de los testimonios. La memoria, en este sentido, juega un papel muy importante en el uso de la historia oral. Puede ayudarnos o puede dificultarnos la tarea, ya que se pueden recurrir a recuerdos sesgados y no se puede garantizar la veracidad de los mismos. Esta selección dependerá del grado de conocimiento, el grado de interés, el de implicación...que el sujeto tenga sobre el hecho que esté narrando.

Por tanto, uno de los peligros o desventajas más comunes del uso de la historia oral es que las personas entrevistadas o encuestadas tienden más a interpretar la historia bajo sus propias vivencias que al fiel relato de la misma, pero que puede ser utilizada esa información para ser contrastada con otras y generar visiones más objetivas. No obstante, a través de ella podemos llegar a interpretar cambios en la conciencia de las personas y, además, encontrar sentido no sólo a lo que nos dicen los libros históricos o la gente relata, sino a lo que se oculta y no se dice.

\section{Algunas recomendaciones para realizar investigaciones de historia oral}

Los pasos que se recomiendan seguir para la elaboración de un proyecto oral pueden variar dependiendo del autor en el que nos basemos, en nuestro caso seguiremos los que Folguera (1994) detalla en su trabajo Como se hace historia oral, ya que sintetiza los puntos clave de este tipo de trabajo teórico-práctico. Según esta autora los pasos a seguir son:

- Definición del objeto-ámbito de estudio

- Revisión de fuentes

- Planteamiento de hipótesis de trabajo

- Plan de trabajo

- Elaboración del cuestionario base

- Diseño de la muestra

- Búsqueda y selección de informantes

- Realización de las entrevistas

- Transcripción de las entrevistas

- Contrastación de los resultados con otras fuentes historiográficas

- Redacción del trabajo y de las conclusiones

Desde nuestra propia experiencia en trabajos de historia oral, creemos conveniente señalar algunos consejos y/o recomendaciones: antes de hacer la entrevista debemos de planificarla, pero no es conveniente llevar una entrevista muy estructurada, ya que ello fomenta la creación de un clima bastante formal y frio, que puede dificultar el dialogo entre el entrevistador y el entrevistado. En definitiva debemos de tener en cuenta la creación de un clima, como un factor muy relevante en el desarrollo de la entrevista.

Durante el transcurso de la entrevista, debemos mantener un primer contacto con nuestro/a entrevistado/a, crear un clima adecuado que facilite la interacción y la recuperación de información. En este momento expondremos cuales son los objetivos y propósitos de nuestro trabajo, además debemos advertirles que si lo desean pueden permanecer en anonimato. Otra de las cuestiones que debemos tener presente es 
recabar la máxima información posible de las vivencias, para ello podemos apoyarnos en documentos, imágenes, visitas, que sustente lo que nuestro entrevistado nos relata.

Otro rol del entrevistador a la hora de recabar información a través de la entrevista es la función de guía, con ello queremos decir que el entrevistador debe seguir unas pautas para poder obtener la información que se ha planteado en los objetivos iníciales. Por otro lado, debemos tener presente que durante la entrevista puede florecer sentimientos, emociones o recuerdos que causen el nuestro sujeto de estudio estrés, miedo, agobio. En este caso, el entrevistador debe mostrar actitudes respetuosas e intentar calmar al sujeto y restablecer la entrevista. Por último, una vez finalizada la entrevista debemos mostrar la gratitud por el esfuerzo realizado.

\section{Conclusiones}

Como ya hemos podido observar a lo largo de la elaboración de este artículo, el uso de la historia oral puede ayudarnos a conocer diversas y distintas realidades sobre las personas, acontecimientos, sucesos, períodos de la vida de una persona, entre otros.

La historia oral se ha posicionado en un lugar muy importante dentro de las metodologías utilizadas para recabar lo histórico, pues, se reconoce que a través del uso de la misma se puede conocer realidades muy distintas, visiones diferentes, corroborativas o cumplimentarías de lo que viene siendo la construcción de los textos históricos. Es decir, por medio del uso de la historia oral se puede llegar a conocer relatos que no están recogidos en los libros de texto que abordan los distintos acontecimientos que han tenido lugar a lo largo de la historia, sino que se da la oportunidad a una persona o un colectivo de ellas de contar sus propias experiencias acerca de un suceso en el que han sido partícipes o testigos y así aportar, bajo sus visiones subjetivas, un aporte que enriquezcan las evidencias seleccionados para ser contadas de manera oficial.

La utilización de la historia oral ha permitido la recuperación de numerosas experiencias y testimonios de personas que, por algún motivo $u$ otro, han sido silenciados en diferentes momentos históricos. Gracias a la historia oral podemos acceder, por ejemplo, a gran repertorio de testimonios que recogen la vida, pensamientos, emociones, sentimientos, necesidades, así como las distintas actividades que realizaban las mujeres en distintas épocas donde no se les daba ni voz ni voto. Del mismo modo, podemos conocer de primera mano la historia de aquellas personas que fueron testigos en primera persona de la guerra, que la vivieron como soldados o como familiares de ellos, por ejemplo, otorgando así la posibilidad de dar voz a los derrotados, a los caídos, a los silenciados, a los marginados de una historia que emana de aquellas personas que poseían más poder.

En educación, el uso de la historia oral tiene vital importancia. En primer lugar, usar la metodología oral para recabar testimonios históricos nos permite humanizar la historia, construirla de manera más personal a través del relato de las vivencias individuales o colectivas de una persona o grupo de ellas. En segundo lugar, al implicarse los alumnos directamente con la consecución de los relatos se puede generar una mayor motivación con lo que están haciendo, por lo que su interés y sus expectativas sobre el aprendizaje aumentarán. Se fomenta así un aprendizaje autónomo, en el que el alumno es el principal constructor de su aprendizaje. Además, para comprender nuestro presente hemos de mirar hacia nuestro pasado, por lo que estos recursos pueden ayudarnos en su comprensión y entender por qué las cosas son ahora cómo son. 
Sin embargo, el uso de la historia oral sigue siendo cuestionado por su fiabilidad, validez y adecuación, ya que hacer uso de este método supone entrar en un campo muy subjetivo del saber, ya que las personas contarán, desde su persona, sus propias visiones acerca de los hechos o sucesos. No obstante, una historia no sería rica en sí misma si no se contrastara con diferentes fuentes de información, independientemente de su tipología, para así otorgar veracidad a los datos.

\section{Bibliografía}

Costa Araújo, H. y Magalhaes, M. J. (2001): "Retazos de vidas. Perspectivas biográficas, profesoras y ciudadanía”. Cadernos coeducaço, Lisboa, Portugal.

Díaz Sánchez, P. y Gago González, J. M. (2006): "La construcción y utilización de fuentes orales para el estudio de la represión franquista". Revista de Historia Contemporánea, $\mathrm{n}^{\circ}$ 6. [http://hispanianova.rediris.es/6/dossier/6d006.pdf]

Egido León, Ángeles (2001). Trabajando con la memoria: exilio y fuente oral. Historia y Comunicación Social, n6, pp.265-279.

Folguera, P. (1994). Cómo se hace historia oral. Madrid: Eudema.

Grana Gil, I. y Alonso Briales, M. (2009): "La educación de las mujeres en Andalucía durante el franquismo a través de las historias de vida", en El largo camino hacia una educación inclusiva. La educación espacial y social del siglo XIX a nuestros días. XV Coloquio de Historia de la Educación. Pamplona, Universidad pública de Pamplona, Vol. II, pp. 101-112.

Jiménez Ramírez, M. (2009). Historia Oral en educación: lo memorable del recuerdo, la importancia de la palabra. En El largo camino hacia una educación inclusiva: la educación especial y social del siglo XIX a nuestros días: XV Coloquio de Historia de la Educación, Pamplona-Iruñea, 29, 30 de junio y 1 de julio de 2009 (pp. 719-726). Universidad Pública de Navarra. 